\title{
Applicable FEM Models for Layered Beams
}

Jakub Javořík, Pavel Nekoksa, Jan Kledrowetz, Rohitha Keerthiwansa

Faculty of Technology, Tomas Bata University in Zlin. Vavrečkova 275, 76272 Zlín. Czech Republic. E-mail: javorik@ft.utb.cz

We need to create appropriate and effective numerical (FEM) model to optimize properties of a composite product. The creation and evaluation of an efficient numerical model that could be used for an analysis of layered composite is the aim of this work. The model has to be able to take into account the properties and layout of the individual layers and must allow effective change of these parameters; thickness, material and number of layers especially. Various models of the same product are created and compared. The models differ in the type of used FEM elements. The results of models (deformation primarily) were compared with the result of analytical computation. Further, time and computational requirements of individual models are also evaluated. Element types used for investigated models are: 1D elements, 2D plane stress solid elements, 2D plane strain solid elements and shell elements. Models created form 1D and shell elements showed a close agreement with the analytical solution, and they provide the appropriate tools for the definition of layered structures and for the analysis of results.

Keywords: FEM model, composite, layered beam

\section{Acknowledgement}

This work and the project is realized with the financial support of the internal grant of TBU in Zlin No. IGA/FT/2017/002 funded from the resources of specific university research.

\section{References}

[1] RUSNAKOVA, S., FOJTL, L., ZALUDEK, M., RUSNAK, V. (2014). Design of material composition and technology verification for composite front end cabs. In: Manufacturing Technology, Vol. 14, No. 4, pp. 607 - 611. UJEP. Czech Republic.

[2] ŽMINDÁK, M., MĚŠKO, J., PELAGIČ, Z., ZRAK, A. (2014). Finite element analysis of crack growth in pipelines. In: Manufacturing Technology, Vol. 14, No. 1, pp. 116 - 122. UJEP. Czech Republic.

[3] DELYOVÁ, I., HRONCOVÁ, D., FRANKOVSKÝ, P. (2014). Analysis of simple mechanism using MSC Adams. In: Manufacturing Technology, Vol. 14, No. 2, pp. 141 - 145. UJEP. Czech Republic.

[4] JAVORIK, J., BILEK, O. (2014). Numerical analysis of bushing of car stabilizer. In: International Journal of Mechanics, Vol. 8, No. 1, pp. 289 - 297. NAUN. USA.

[5] JAVORIK, J. (2016). Numerical Optimization of Large Shade Sail Support. In: Manufacturing Technology, Vol. 16, No. 4, pp. 707-712. UJEP. Czech Republic. 